\title{
Políticas educativas para crianças de 0 a 3 anos ${ }^{\star}$
}

\author{
Vera Maria Ramos de Vasconcellos ${ }^{\star}$ \\ Universidade do Estado do Rio de Janeiro, Rio de Janeiro, RJ, Brasil
}

\begin{abstract}
Resumo
Este artigo foi construído a partir de reflexões teórico-práticas realizadas no Núcleo de Estudos da Infância: Pesquisa \& Extensão (NEI:P\&E), ${ }^{1}$ que se insere na Linha de Pesquisa Infância, Juventude e Educação do ProPEd/UERJ. Por tradição nossos estudos abarcam questões de desenvolvimento humano de crianças, de suas familias e de seus educadores/professores. A perspectiva teórica é sócio-histórica-cultural, tendo como orientação básica os trabalhos desenvolvidos por Lev Vigotski e Henri Wallon. O campo de pesquisa envolve três municípios: Rio de Janeiro, Juiz de Fora e Niterói. Em todos eles, o foco do estudo recai sobre as políticas públicas de educação infantil entre os anos 2009 e 2013, as tensões implicadas entre o texto das políticas e as práticas cotidianas, além das suas implicações histórico-culturais que orientam e distinguem os enfoques em cada municipio.
\end{abstract}

Palavras-chave: educação infantil; políticas educacionais; abordagem sócio-histórica-cultural

\section{Education policy for children from 0 to 3 years old}

\begin{abstract}
This article was built out of theoretical and practical reflections done at Núcleo de Estudos da Infância: Pesquisa \& Extensão (NEI:P\&E). The Nucleo of Childhood Studies: Research \& Extension is part of the Research Group Childhood, Youth and Education from PROPED/UERJ. By tradition our studies cover issues linked with Human Development (children, their families, teachers and helpers). Our theoretical perspective is socio-historical and cultural, based on the work developed by Lev Vygotsky and Henri Wallon. The research is done on three municipalities: Rio de Janeiro, Juiz de Fora e Niterói. The Educational Policy of Early Education, from 2009 to 2013, is the focus of the studies. The tensions existented between the text of the policies and everyday practices, in addition to its historical and cultural implications is which guides and distinguishes the approaches in each municipality.
\end{abstract}

Keywords: infant education; educational policy; social-historical \& cultural approach

A partir da promulgação da Constituição Federal/1988, a educação infantil em creches e pré-escolas passa a ser um direito das crianças de zero a seis anos, sendo também dever do Estado a garantia desse atendimento (BRASIL, 1988, art. 208). O Estatuto da Criança e do Adolescente (BRASIL, 1990) e, posteriormente, a LDBEN 9394 (BRASIL, 1996) surgem com o objetivo de concretizar e regulamentar seus dispositivos nas diferentes esferas da sociedade. Foi, especificamente, a partir da promulgação da LDBEN 9394/96 que as instituições públicas passaram a ser obrigadas a oferecer às crianças de 0 a 6 anos o ensino gratuito e público em unidades de educação infantil, separando-as por faixa etária, de modo que as crianças de zero a três anos devem ser recebidas em creches e de 4 a 5 anos e 11 meses em pré-escolas (BRASIL, 1996, art. 30). Tornando-se um direito das crianças, o Estado passou a ter o dever de oferecer os estudos, conforme mencionado, cabendo aos municípios planejar o recebimento das instituições que prestavam esse serviço em outras esferas (BRASIL, 1996, art.4, art. 11), pois, diz a Lei, que as mesmas deveriam integrar-se aos sistemas de ensino municipal num prazo de três anos (BRASIL, 1996, art. 89). ${ }^{2}$

\footnotetext{
^Grupo de Pesquisa Núcleo de Estudos da Infância: Pesquisa \& Extensão (NIEPE), Coordenado por Vera Maria Ramos de Vasconcellos.

$\star \star$ Endereço para correspondência: Universidade do Estado do Rio de Janeiro, Centro de Educação e Humanidades, Faculdade de Educação. Rua São Francisco Xavier, 524, 12 andar, sala 12005 Bloco F - Maracanã. CEP 20550900 - Rio de Janeiro, RJ - Brasil.E-mail: vasconcellos.vera@gmail.com. 'O Grupo de Pesquisa tem sede na Faculdade de Educação da UERJ, sala 12005, Bloco F.

Este tema já foi amplamente discutido nos artigos: Vasconcellos (2001), Aquino, Lanter e Vasconcellos (2003) e Aquino e Vasconcellos (2011).
}

As repercussões da LDBEN 9394/96 no município do Rio de Janeiro e nas demais regiões deram origem a um período de mudanças significativas no cotidiano das creches que, historicamente, constituíram-se sob os padrões de organização das secretarias de desenvolvimento sociais. A partir de setembro de 2003, dois anos após o prazo estipulado pela Lei, o poder público municipal do Rio de Janeiro, transferiu a responsabilidade pelo atendimento das creches municipais para a Secretaria Municipal de Educação (SME).

Em 2007, a SME organiza concurso público para o cargo de agente auxiliar de creche, que aconteceu regionalmente, isto é, por CRE. ${ }^{3}$ Após inúmeras manifestações contrárias produzidas no conjunto do Departamento de Estudos da Infância (DEDI/UERJ) e junto ao Fórum Permanente de educação infantil do Estado do Rio de Janeiro (existente desde novembro/1996) ainda nos sentimos impotentes para desfazer o enorme equívoco cometido pela gestão que saía e deixava um desserviço às políticas públicas de educação infantil. Por isso, no final 2008, decidimos focalizar em nossos estudos a gestão, que iniciava em 2009, na Secretaria Municipal de Educação, buscando analisar se haveria uma nova visão e propostas para a educação infantil no município. Convidamos, então, algumas ex-alunas da UERJ, que atuaram como educadoras na creche institucional de nossa pesquisa anterior, que haviam prestado o concurso público e foram aprovadas como agentes auxiliares de creche. Elas passaram a ser copesquisadoras, no "chão da escola"; isto é, começaram a refletir conosco o que acontecia no fazer pedagógico diário das creches. Essa foi a motivação para ${ }^{3}$ A cidade do Rio de Janeiro é subdividida em 10 Coordenadorias Regionais de Educação. 
o desenho e a submissão à FAPERJ da pesquisa "Agente Auxiliar de Creche Educadores da Infância Carioca" (FAPERJ, E-26/102.961/2008). Entendemos que a qualidade das políticas públicas de educação para a infância passa pela formação do profissional que nela atua, não só como sujeito da ação, mas e, principalmente, como "autor e ator" reflexivo do seu próprio fazer. Passa também, por um maior conhecimento sobre as questões da infância, psicologia da criança, desenvolvimento humano e outros temas. Por essa razão, ao longo dos últimos cinco anos desenvolvemos uma série de pesquisas complementares, abrangendo diferentes municípios que serão descritas, em seus detalhes, ao longo deste texto.

No Rio de Janeiro, nos últimos cinco anos, vimos acompanhando de perto o trabalho educacional desenvolvido por agentes auxiliares e professores de educação infantil de algumas creches municipais, através do relato desses profissionais na construção de novos saberes, sobre seus envolvimentos com as equipes locais e famílias de suas crianças. Estamos, assim, testemunhando e a implementação de uma política pública municipal (2009-2013), quanto à formação em serviço e pesquisando em interlocução direta com educadores no "chão da escola" os seus fazeres cotidianos. Esse contexto histórico nos levou a dar maior atenção às mudanças ocorridas nas políticas públicas de educação infantil, na cidade do Rio de Janeiro, a partir da normatização do funcionamento das creches públicas municipais. ${ }^{4}$ Para tal, as discussões sobre ciclo de políticas (policy cycle approach) de Stephen Ball (1994) e seus colaboradores têm sido tomado como referencial teórico complementar. Sua contribuição é oferecer subsídios para analisar os textos das políticas, suas produções e a reinterpretação, enfrentamento e recriação das políticas pelos sujeitos que as vivenciam nas creches, desde a sua inclusão no sistema de ensino até o momento atual.

Abordaremos, neste trabalho, alguns resultados das pesquisas realizadas de 2009 a 2011,5 que visaram a identificar as tensões existentes na chegada às creches dos agentes auxiliares de creche, oriundos do concurso público de $2007,{ }^{6}$ entendendo-os como os então oficialmente "alçados" educadores da infância carioca. Complementar ao primeiro, o segundo projeto (2012 - 2013) ${ }^{7}$ objetivou acompanhar as mudanças ocorridas nas creches, principalmente no trato das questões do "cuidar e educar" dos bebês e das crianças pequenas, após a chegada dos professores de educação infantil, ${ }^{8}$ aprovados no concurso de $2011 .{ }^{9}$

Nos diferentes momentos da pesquisa, buscamos interpretar os meandros das diferentes facetas da política pública estudada à luz do ciclo de políticas de Stephen Ball (contexto de influência, da produção de ${ }^{4}$ Resolução SME/RJ n ${ }^{\circ} 816$ de 01/2004.

${ }_{5}^{5}$ Agente Auxiliar de Creche: Educadores da Infância Carioca/FAPERJ -

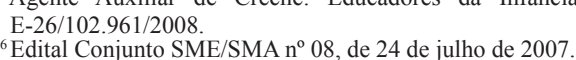

${ }^{7}$ O Percurso de agentes auxiliares e Professores na Creche: da nomeação

à construção de uma Pedagogia para a Infância Carioca (FAPERJ E-26/110.407/2012)

${ }^{8}$ Projeto de lei $\mathrm{n}^{\mathrm{o}} 701 / 2010$, cria no quadro permanente do poder executivo do

Município do Rio de Janeiro a categoria funcional de professor de educação infantil.

${ }^{9}$ Edital n ${ }^{\circ}$ 91, de 25/10/2010

Fractal, Rev. Psicol., v. 27 - n. 1, p. 68-73, 2015 texto e da prática) e também das noções de "sentido e significado" de Lev Vigotski. Diferentes instrumentos de mediação, carregados de significados e conceitos coerentes com objetivos e funções foram-se aprimorando ao longo da história da pesquisa.

O trabalho na perspectiva sócio-histórico-cultural enfatiza a interação dos profissionais, deles com as crianças e suas famílias e das crianças entre si. Valoriza o papel da mediação não só dos sujeitos, mas também da qualidade dos equipamentos, artefatos/ferramentas culturais que nas diferentes pesquisas tomaram formatos próprios como os brinquedos, os projetos e os planejamentos.

Em sua maioria, os estudos estão apoiados em procedimentos de análise de cunho qualitativo e visam a apreender os sentidos que constituem o conteúdo do discurso dos sujeitos participantes e os significados partilhados em encontros coletivos, sejam cursos de formação, sessões reflexivas ou grupos focais. Consequentemente, compreender os sentidos produzidos e os significados compartilhados implica analisar também o contexto individual, histórico, social e cultural nos quais os AAC, PEIs e gestoras estão inseridos. A categoria "sentido" destaca a singularidade historicamente construída, pois não significam apenas uma resposta única, mas formas diferenciadas de percepção das histórias vividas pelos sujeitos: algumas vezes incoerentes, outras complacentes, outras parciais. $\mathrm{O}$ "sentido" é construído através das relações sociais no qual os signos, "entendidos como instrumentos convencionais de natureza social, são os meios de contato com o mundo exterior e também do homem consigo mesmo e com a própria consciência" (AGUIAR, 2000, p. 129).

Ao privilegiar Lev Vigotski como interlocutor teórico para as pesquisas aqui apresentadas, em interlocução com autores nacionais como Pino (2005), Gonzales-Rey (2005, 2010), Aguiar (2006) e Aguiar e Ozella (2006), foi necessário olhar o conhecimento como possibilidades, a partir das categorias "sentido e significado" e optar por metodologias nas quais a própria pesquisa seja um momento de arriscar novos olhares e novas vivências e não somente um momento de reconhecer ou de aplicar metodologias já consolidadas que darão conta de parte dos resultados. Retornando a autores clássicos, Newman e Holzman (2002, p. 47) nos lembram que "nem a mão nem a mente sozinhas bastam"; os instrumentos e ferramentas que elas empregam acabam por moldá-las. O que para esses autores e para nós, também, significa pensar a metodologia "instrumento-e-resultado" é entender que o conhecimento é construído a partir da retomada de diversos saberes, de diferentes olhares e múltiplas referenciais. Os diferentes discursos são reorganizados e ressignificados de forma singular, permitindo uma reflexão sobre a prática e a construção de um discurso sobre ela. Na visão de conhecimento prospectivo (VYGOTSKY, 1996), isso significa investir na produção das pesquisas, no aprendizado do novo, no lidar com o imprevisto, com o súbito, com as surpresas e o repentino. O que significa abandonar 
saberes fossilizados, controles previsíveis e ver na possibilidade do novo a legitimidade de outros modos de olhar e de fazeres diferentes, descontínuos e inesperados.

\section{Metodologia de pesquisa}

Definir uma única metodologia de pesquisa é difícil, pois ela tem se constituído e se modificado à medida que os trabalhos acontecem. Na pesquisa central, trabalhamos em diálogo quinzenal com as copesquisadoras, analisando com elas nossas questões de fundo "O que é ser agente auxiliar de creche"? e "O que é ser educador da infância carioca?”. Para tal, no segundo semestre de 2008 fizemos entrevistas individuais gravadas em vídeo com as educadoras que, naquele momento, estavam na creche institucional. Com essas entrevistas, buscamos registrar as experiências, anteriormente, vividas na educação infantil, tanto em relação à creche, quanto às famílias de seus educandos. Quando o primeiro semestre de 2009 começou e as educadoras já estavam alocadas nas suas respectivas creches municipais, ${ }^{10}$ realizamos dez "sessões reflexivas". ${ }^{11}$ Tínhamos por objetivo refletir sobre a experiência anterior na creche institucional e a nova experiência nas municipais. Realizamos análises e reflexões conjuntas com registros minuciosos das atividades cotidianas das mesmas. Solicitávamos a cada copesquisadora que fizesse seu próprio registro, chamados por nós de "Diário de Bordo". ${ }^{12}$ Naquele momento ainda estávamos aguardando a aprovação, do Comitê de Ética, ${ }^{13}$ da Secretaria Municipal de Saúde. Durante o período de espera, trabalhamos só com as copesquisadoras. A partir do segundo semestre de 2009, já com o parecer positivo do Comitê de Ética, ${ }^{14}$ partimos então para a negociação com as diretoras, tendo ficado a encargo das copesquisadoras apresentar o projeto e nossa carta de solicitação de parceira.

Nos encontros com as diretoras definimos as formas de intervenção possíveis. Alguns dos eixos centrais acordados: (i) cada copesquisadora seria uma investigadora intencional de suas próprias práticas e "interlocutora privilegiada" de sua unidade; (ii) faríamos reuniões mensais com a equipe gestora e planejaríamos juntas os Centros de Estudos Coletivos; ${ }^{15}$ (iii) nossas visitas às instituições se dariam por convite das mesmas. Muitos foram os temas que compuseram a nossa pesquisa, entre eles o que aconteceu todos os anos e em todas as creches foi a inserção de bebês e suas famílias. Esse braço da pesquisa tinha por objetivo: (i) investigar o processo de inserção de bebês/crianças e suas famílias à creche num acompanhamento triangulado e longitudinal com diferentes grupamentos de crianças; (ii) observar, longitudinalmente, a permanência e as interações (criança-criança e criança-

${ }^{10}$ As creches foram escolhidas por elas, a partir de critérios pessoais, sem nenhum tipo de interferência de nossa parte.

${ }^{11}$ Sessões reflexivas são encontros de discussões que contam com a participação de pesquisadores e educadores das creches.

${ }^{12}$ Cada uma fazia os seus registros e depois discutíamos as diferentes modalidades (Vasconcellos et al, 2008; Vasconcellos, 2008).

${ }^{13}$ A gestão de 2009 tinha um modelo específico para este tipo de pedido, o que nos fez reescrever o projeto e reapresentá-lo ao Comité.

${ }^{4}$ Processo No 07/001925/2012.

${ }^{5}$ Centros de Estudos Coletivos com todos os agentes auxiliares de creches (100). Realizados na UERJ nos meses de setembro, outubro e novembro/2009, com carga horária de 14 horas mensais ( $6^{\mathrm{a}}$ feira $10 \mathrm{~h}$ e Sábado $4 \mathrm{~h}$ ), totalizando 42 horas de trabalho coletivo. Em 2010, outubro e novembro e em 2011, Junho, 16 , antes da chegada dos PEIs- professores de educação infantil. -berçarista) dos novos bebês/crianças. Os registros foram feitos não só de forma escrita, mas e, principalmente, por meio de fotografias das crianças em diferentes momentos de seu desenvolvimento e suas interações nas atividades propostas pelas educadoras (AAC e PEI).

A partir de então as questões que têm norteado nossas análises mais gerais são: "Como os educadores (agentes auxiliares e professores) analisam as atividades de cuidar/educar e brincar, propostas no espaço/lugar e tempo da creche?"; Como se dá a multidocência ${ }^{16}$ e as atividades organizadas e refletidas por eles em conjunto?"; "Quais as reações das crianças a tais propostas?"

\section{Outras Pesquisas em andamento}

Entre os anos de 2011 a 2013, Maciel Cristiano da Silva (mestrando/PROPED) realiza um estudo de follow-up com três crianças com necessidade educacionais especiais (NEE) e suas mães, sujeitos de investigações concluídas em 2009, em creches do município do Rio de Janeiro. ${ }^{17} \mathrm{Na}$ nova dissertação, foram entrevistadas as mães das referidas crianças para compreender os percursos de escolarização de seus filhos, desde a saída da creche. Buscou-se entender as expectativas das mães em relação ao desenvolvimento e escolarização de seus filhos com NEE. Em 2013, as três crianças estão em instituições de "educação especial", duas em instituições privadas de caráter filantrópico e somente no sistema público educacional da cidade.

A pesquisa "O perfil dos professores de educação infantil da Cidade do Rio de Janeiro", desenvolvida por Marcia Gil (2013) (mestranda/PROPED), busca conhecer quem são os profissionais oriundos do primeiro concurso realizado para tal função. Foi utilizado como instrumento produção de dados um questionário digital, enviado às unidades, para ser disponibilizado a todos os PEIs, com o objetivo de conhecer a formação, expectativas e atuação dos mesmos junto às crianças em idade de creche. Em complementação ao primeiro instrumento, foram realizados dois grupos focais com as PEIs que foram antes agentes auxiliares de creche, com objetivo de saber como está sendo construída a identidade pessoal e coletiva de ser professora de educação infantil, no município do Rio de Janeiro. Os resultados da pesquisa pretendem orientar políticas públicas que favoreçam a formação continuada desses professores, vislumbrando a produção de uma pedagogia para a infância carioca.

Outra pesquisa de mestrado intitulada "PROINFANTIL $^{18}$ no município do Rio de Janeiro: concepções de criança nos Projetos de Estudos", desenvolvida por Maria Ignez Ferreira Campos (2014) (mestranda/PROPED) tem por objetivo investigar os sentidos construídos sobre a formação pedagógica em educação infantil, na

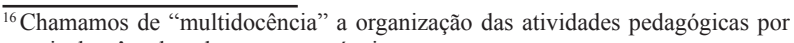
mais de três educadores, responsáveis por um mesmo agrupamento.

${ }^{17}$ OLIVEIRA, Miriam P. R. de. Crianças Focais: a triangulação educação-famíliasaúde na creche. 2009, 141 p. Dissertação (Mestrado em Educação) UERJ. Rio de Janeiro. SILVA, Maciel Cristiano da. Infância, Educação e Inclusão: um estudo de caso. 2009. Monografia (Graduação de Pedagogia) UERJ. Rio de Janeiro.

${ }^{18}$ PROINFANTIL - Programa de Formação Inicial para Professores em Exercício na educação infantil - é um Projeto do Ministério da Educação - Secretaria de Educação Básica e da Secretaria de Educação a Distância. No Rio de Janeiro foi operacionalizado em parceria com a Universidade Federal do Rio de Janeiro, o Governo do Estado do Rio de Janeiro e o Governo Municipal do Rio de Janeiro. 
produção da identidade profissional e nas concepções de professor de educação infantil, criança, infância e educação infantil. A análise se dá a partir do trabalho final projetos de estudos - produzidos pelos agentes auxiliares de creche, participantes de uma AGF. ${ }^{19}$ São analisadas as políticas públicas no município do Rio de Janeiro, que levaram à adoção do PROINFANTIL, a partir do referencial de ciclo de políticas (policy cycle approach) de Stephen Ball e Jefferson Mainardes (2011) e seus colaboradores e das contribuições de Lev Vigotski (2000) como parceiro privilegiado de análise nas redes, textos e sistemas de significados numa perspectiva histórico-cultural.

A pesquisa de mestrado desenvolvida por Alessandra Savaget Almeida (mestranda/PROPED), "Primeira Infância Completa: uma política pública da cidade do Rio de Janeiro voltada para as famílias das crianças de creche", visa a analisar o programa Primeira Infância Completa (PIC) nas três creches públicas municipais envolvidas na pesquisa. O PIC é um projeto socioeducativo que acontece aos sábados, para crianças (e famílias) que não conseguiram vaga na jornada semanal. Enquanto as crianças participam de atividades pedagógicas com os profissionais da creche, seus responsáveis participam da roda de conversa (Escola de Pais), realizada, em sua maioria, por professores da própria creche, contrariando a ideia inicial do programa que visava à intersetorialidade (participação de outras áreas como saúde e assistência social). Para os usuários do Cartão Família Carioca, a frequência a esses encontros é obrigatória. A pesquisa faz um recorte histórico-metodológico no período 2009 2012, que compreende o início do programa até a avaliação externa de consultor contratado pela UNESCO. Busca fazer um paralelo entre a proposta oficial do programa e as impressões de cada um dos diferentes atores sociais envolvidos: profissionais de creche - gestoras, professores e agentes auxiliares de creche e famílias.

A pesquisa de mestrado de Erika Jennifer Honorio Pereira tem como objetivo analisar as políticas públicas do município do Rio de Janeiro com relação à literatura para a criança de zero a três anos. Procura investigar em que medida as políticas do município dialogam com as políticas nacionais (Diretrizes Curriculares Nacionais, o Plano Nacional e o Referencial Nacional para a educação infantil). Busca verificar de que forma as políticas públicas efetivam-se nas creches. Será desenvolvida uma pesquisa de campo com levantamento do acervo literário das três creches da pesquisa, bem como dos critérios de seleção para as compras das obras literárias que compõem o acervo da creche, e as temáticas que costumam ser contempladas na escolha do livro.

Em 2011 e 2012, no âmbito do doutoramento, começam pesquisas sobre as políticas públicas em outros municípios além da cidade do Rio de Janeiro. Uma delas, foi desenvolvida por Alexsandra Zanetti (2013), intitulada "Discursos e intervenções: a integração das creches pú${ }^{19} \mathrm{AGF}$ - Agência Formadora - núcleo de apoio pedagógico e administrativo ao PROINFANTIL, composta por uma equipe de professores formadores, disponibilizados pela Secretaria Estadual de Educação, um para cada área temática do currículo (Linguagens e Códigos; Identidade, Sociedade e Cultura; Matemática e Lógica; Vida e Natureza; Fundamentos da Educação; Organização do Trabalho Pedagógico e Língua Estrangeira).

Fractal, Rev. Psicol., v. 27 - n. 1, p. 68-73, 2015 blicas no sistema municipal de ensino de Juiz de Fora-MG”, cujo objetivo é analisar como as coordenadoras/ diretoras das creches públicas do município em questão compreendem o processo de transição da gestão político-administrativa das creches da assistência social para a Secretaria de Educação, quando confrontadas pelas perspectivas anunciadas no discurso oficial. Para isso, utiliza-se da abordagem do "Ciclo de políticas", sistematizada pelo sociólogo inglês Stephen Ball e seus colaboradores, de análise documental, sessões reflexivas, além de pesquisa bibliográfica.

A segunda, realizada por Márcia Maria e Silva, iniciada em 2012 analisa as práticas de formação do literário na educação infantil no município de Niterói, a partir de observações realizadas em uma Unidade de Educação Infantil (UMEI). A pesquisa se justifica pela valorização das culturas, produções artísticas e históricas próprias do contexto social da criança, garantindo a liberdade de criação e o acesso às fontes de cultura, como estabelece o ECA ${ }^{20}$ e outros documentos oficiais. Nesta pesquisa a noção de zona de desenvolvimento proximal em Vigotski se apresenta como fio condutor de ações de ensinar e aprender. Acentua a confiança de que se pode impulsionar o sujeito a aprender através de interações sociais que o levem a tencionar o já sabido, a vivenciar situações-problema, a gerar transformações, a reinventar o novo. As reflexões propostas nesse trabalho sobre políticas e práticas de formação do leitor literário na educação infantil busca contribuir para desnaturalizar determinadas práticas pedagógicas presas às ideias de deleite, prazer e brincadeira, sem relacioná-las a conhecimentos sobre desenvolvimento infantil e ao compromisso político, ético, estético implicado em toda e qualquer ação para a formação literária e humana dos pequenos leitores.

Dois outros trabalhos são desenvolvidos pelas professoras doutoras Antonia Simone Gomes (2013) (UEMG) e Adelaide Alves Dias (2013) (UFPB), presentes no grupo em pós-doutoramento.

O primeiro, intitulado "Práticas de interlocução reflexivo-colaborativas na construção da identidade dos professores de educação Infantil", se desenvolve com um grupo de alunos de graduação no curso de Pedagogia da UERJ, matriculados na disciplina Pesquisa e Prática Pedagógica, que atuam ou pretendem atuar como professores de educação infantil. O objetivo é proporcionar um convívio educacional democrático e analisar como o intercâmbio entre os alunos iniciantes e os alunos/professores que já atuam na educação infantil gera uma ação dialógica no processo de formação docente que contribui para a consolidação da identidade do professor de educação infantil. O campo de investigação será a sala de aula e temos como pressuposto uma visão de educação que encontra sustentação na construção de práticas pedagógicas que concebem a mediação social como eixo de aprendizagem e desenvolvimento e a brincadeira como suporte do trabalho na educação infantil.

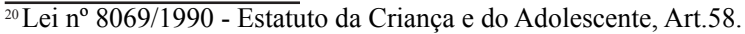


O segundo, "educação infantil, direitos humanos e políticas públicas: uma análise sobre os processos de institucionalização das creches na cidade do Rio de Janeiro", objetiva analisar os processos de institucionalização das creches públicas municipais e as práticas educativas que se desenvolvem com crianças de zero a cinco anos no Rio de Janeiro, de modo a contribuir com a implementação de políticas públicas que garantam a efetiva qualidade educacional e tenham como propósito ampliar e fortalecer a cidadania e os direitos humanos das crianças pequenas. Tem como foco os seguintes elementos: (i) a formação do/a professor/a; (ii) a proposta pedagógica e a organização dos espaços e dos tempos de aprendizagens e de convivência; (iii) a atual concepção/compreensão da criança enquanto sujeito de direitos; (iv) a qualidade do atendimento em seus múltiplos aspectos. São questões da pesquisa: quais e como as situações do cotidiano das instituições de educação infantil do Rio de Janeiro se convertem em contextos de promoção de desenvolvimento integral, com vistas a garantir o direito da criança pequena à educação infantil de qualidade?; e como as recentes mudanças no ordenamento jurídico-político com relação à educação infantil tem contribuído para a implementação de políticas públicas que visem a assegurar uma educação infantil de qualidade? Serão sujeitos dessa pesquisa os gestores, professores e auxiliares de educação infantil.

\section{Considerações finais}

Em síntese, todas as pesquisas aqui discutidas acompanharam, a partir da utilização de metodologias diversas de investigação, a implementação de novas políticas municipais de educação, tendo como interlocutores principais os profissionais do "chão da escola". Essas diferentes formas de estudo resultaram em um aperfeiçoamento profissional de todos os envolvidos, contribuindo para a produção de projetos político- pedagógicos singulares em cada unidade.

Esperamos, assim, que nossas pesquisas possam contribuir para a formação do profissional de educação infantil, pensando o educador como aquele que propicia espaços de criação e que valoriza os processos imaginativos, a dimensão simbólica e a construção do conhecimento, tendo a criança como protagonista de seu processo de aprendizagem e desenvolvimento.

Com as pesquisas aqui apresentadas, podemos dar testemunho de que um trabalho integrado e de intercâmbio da universidade (UERJ) com Secretarias Municipais de Educação (ou pelo menos com algumas unidades que compõem as Secretarias), abre novos horizontes, propiciando melhor formação inicial (alunos de pedagogia) ou continuada para os profissionais da Educação, inclusive a formação em pesquisa. Além disso, possibilita também maiores reflexões sobre a melhoria de qualidade da educação infantil existentes em cada creche.

\section{Referências}

AGUIAR, W. M. J. Reflexões a partir da Psicologia SócioHistórica sobre a categoria "consciência". Cadernos de Pesquisa, [S.1.], n. 110, p. 125-142, jul. 2000.
AGUIAR, W. M. J. A pesquisa junto a professores: fundamentos teóricos e metodológicos. In:__. Sentidos e significados do professor na perspectiva sócio-histórica: relatos de pesquisa. São Paulo: Casa do Psicólogo, 2006.

AGUIAR, W. M. J.; OZELLA, S. Núcleos de significação como instrumento para a apreensão da constituição dos sentidos. Psicologia: Ciência e Profissão, Brasília, v. 26, n. 2, p. 222-245, jun. 2006.

ALMEIDA, A. S. Primeira Infância Completa: uma política pública da cidade do Rio de Janeiro voltada para as famílias das crianças de creche. Pesquisa de pós-doutorado - Universidade do Estado do Rio de Janeiro, Rio de Janeiro

AQUINO, L. M. L. Ordenamento legal para educação infantil e desafios para os gestores municipais. In VASCONCELLOS, Tânia (org). Reflexões sobre infância e cultura. Niterói, EDUFF, 2008. p. 185-206.

AQUINO, L. M. M. L. L.; VASCONCELlOS, V. M. R. Orientação Curricular para a educação infantil: Referencial Curricular Nacional e Diretrizes Curriculares Nacionais. In: Vasconcellos, V.M.R.. (Org.). Educação da Infância: História e Política. 2 ed. Niterói: Editora da UFF, 2011

BALL, S. Education reform: a critical and post-structural approach. Buckingham: Open University Press, 1994.

BALL, S. \& MAINARDES, J (Org.) Politicas Educacionais: questões e dilemas. São Paulo: Cortez, 2011

BRASIL. Congresso Nacional. Constituição da República Federativa do Brasil. 1988. Disponível em: <http://www. planalto.gov.br/ccivil_03/constituicao/constituicaocompilado. $\mathrm{htm}>$. Acesso em: 12 maio 2013.

BRASIL. Ministério da Justiça. Lei $n^{\circ} 8069$, de 13 de julho de 1990. Dispõe sobre o Estatuto da Criança e do Adolescente e dá outras providências. Diário Oficial da União, Brasília, DF, 16 jul. 1990.

BRASIL. Ministério da Educação e do Desporto. Lei $n^{\circ} 9394$, 20 de dezembro de 1996. Estabelece as Diretrizes e Bases da Educação Nacional. 1996. Disponível em: < http://www.planalto. gov.br/ccivil_03/leis/19394.htm>. Acesso em: 13 jun. 2013.

CAMPOS, M. I. F. O PROINFANTIL no municipio do Rio de Janeiro: concepções de criança nos Projetos de Estudos. 2014. Dissertação (Mestrado)_Programa de Pós Doutorado em Educação - Universidade do Estado do Rio de Janeiro, Rio de Janeiro, 2014.

DIAS, A. A. educação infantil, direitos humanos e políticas públicas: uma análise sobre os processos de institucionalização das creches na cidade do Rio de Janeiro. Pesquisa de pósdoutorado - Universidade do Estado do Rio de Janeiro, Rio de Janeiro, 2013.

GIL, M. O perfil dos Professores de educação infantil da Cidade do Rio de Janeiro. 2013. Dissertação (Mestrado)-Programa de Pós-graduação em Educação - Universidade do Estado do Rio de Janeiro, Rio de Janeiro, 2013.

GOMES, A. S. Práticas de interlocução reflexivo-colaborativas na construção da identidade dos professores de educação infantil. Pesquisa de pós-doutorado - Universidade do Estado do Rio de Janeiro, Rio de Janeiro, 2013

GONZÁLEZ-REY, F. L. Pesquisa qualitativa em psicologia: caminhos e desafios. São Paulo: Pioneira Thomson Learning, 2005. 
GONZÁLEZ-REY, F. L. Pesquisa Qualitativa e Subjetividade: os processos de construção da Formação. São Paulo: Cengage Learning, 2010.

MOREIRA, A.R.P. \& VASCONCELLOS, V.M.R. de Ambientes de Desenvolvimento na Creche, $1^{\text {a }}$ GRUPECI, Juiz de Fora, 2008.

NEWMAN, F.; HOLZMAN, L. Lev Vygotsky: o cientista revolucionário. São Paulo: Loyola, 2002.

PEREIRA, E. J. H. "Tia existe flor preta?": educar para as relações étnico-raciais. 2013. Dissertação (Mestrado) Programa de Pós-graduação em Educação - Universidade do Estado do Rio de Janeiro, Rio de Janeiro, 2013.

PINO, A. As Marcas do Humano: às origens da constituição cultural da criança na perspectiva de Lev. S. Vigotski. São Paulo: Cortez, 2005.

SILVA, M. M. Formação do leitor literário infantil: infância, literatura e docência. 2014. Qualificação do Projeto de Tese (Doutorado)-Programa de Pós-Graduação em Educação Universidade do Estado do Rio de Janeiro, Rio de Janeiro, 2014.

SILVA, M. C. Trajetórias Educacionais De Crianças Com Necessidades Especiais No Município Do Rio De Janeiro. Dissertação (Programa de Pós-graduação em Educação) Universidade do Estado do Rio de Janeiro, 2013.

VASCONCELLOS, V. M. R. Crianças e Famílias na Creche: Como Se Dá Esta Inserção? VII ENCONTRO NACIONAL SOBRE O BEBÊ NASCIMENTO Antes e Depois - Cuidados em Rede, maio 2008.

VASCONCELLOS, V. M. R Formação dos Profissionais de educação infantil: reflexões sobre uma experiência. Em Aberto $\mathrm{N}^{\circ} 18$, p. $98-111,2001$

VYGOTSKY, L. Teoria e Método em Psicologia. São Paulo: Martins Fontes, 1996.

VYGOTSKY, L. Pensamento e Linguagem. São Paulo: Martins Fontes, 2000.

ZANETTI, A. Discursos e intervenções: a integração das creches públicas no sistema municipal de ensino de Juiz de Fora-MG. 2013. Qualificação do Projeto de Tese (Doutorado) Programa de Pós-graduação em Educação - Universidade do Estado do Rio de Janeiro, Rio de Janeiro, 2013.

Recebido em: 29 de agosto de 2013

Aceito em: 05 de novembro de 2014 